\title{
Too intelligent for our own good
}

Sir - Intelligence may be a deadly pathogen that, given sufficient time, will infect all habitable planets. It rapidly learns to obtain energy by reversing the geochemical fluxes that hitherto maintained the surface conditions of the planet stable and habitable.

Such changes may be very rapid. At the current incremental rate, forced by intelligent biota, atmospheric carbon dioxide will be 600 parts per million by the year 2050. This is a non-trivial increase over the 180 and 280 p.p.m. indicated by ice-core data for glacial and interglacial periods respectively over the previous 160,000 years ${ }^{1}$.

In his Review Article in Nature,

Timothy Lenton ${ }^{2}$ did not discuss this most interesting aspect of Gaia - its current manifestation. I think it is now agreed that self-regulating feedback by the pre-sentient biosphere maintained, and may have produced, an atmospheric composition and a mean global surface temperature conducive to the evolution of biota likely to develop intelligence. What is not clear is whether the sentient part of the biosphere will develop sufficient self-control to restore geochemical fluxes to the state necessary to maintain the surface of the Earth habitable.

In short, is intelligence a pathogen to which the biosphere can adjust, or is it terminal? Perhaps it is as well that we cannot yet observe other habitable planets, to discover what became of their sentient life!

\section{Alan Longhurst}

Galerie l'Acadie, Place de l'Eglise,

46160 Cajarc, France

Sir - Biology, geochemical cycles and climate are intimately linked. There are many feedbacks, both stabilizing and destabilizing, involving biology, geochemical cycles and climate. Obviously, systems with strong stabilizing feedbacks are more likely to persist than systems lacking such stabilization. And species that are components of stable systems are more likely to persist than species that are components of unstable systems. These simple observations can explain the prevalence of important stabilizing feedbacks on Earth involving biology, geochemistry and climate.

Is there such a thing as a negative feedback involving biology, geochemistry and climate that is not "Gaian regulation"? If all such feedbacks are ipso facto Gaian, then "Gaian regulation" is but old wine in a new bottle.

Ken Caldeira

Climate System Modeling Group,

Lawrence Livermore National Laboratory,

7000 East Ave, L-103, Livermore,

California 94550, USA

e-mail:kenc@llnl.gov

1. Barnola, J. M., Raynaud, D., Korotkevich, Y. S. \& Lorius, C. Nature
329, 408-414 (1987).

2. Lenton, T. M. Nature 394, 439-447 (1998).

\section{Religious belief doesn't weaken scientific mind}

Sir — Larson and Witham (Nature 394, 313 ; 1998) address the controversial topic of religious belief. They quote Leuba, who attributed higher levels of disbelief and doubt to "superior knowledge, understanding, and experience", and Atkins, who states "You can clearly be a scientist and have religious beliefs. But I don't think you can be a real scientist in the deepest sense of the word because they are such alien categories of knowledge". Both opinions discredit religious scientists.

The essence of science, and moreover of the human mind, makes the process of acquiring knowledge infinite. Take matter as a simple example. The earliest attempts to define it divided matter into simple categories, then abstraction grew, and the concept of the atom was developed. We could not be content with indivisible entities, so we discovered protons, neutrons and electrons. We then began the search for subatomic particles. And so it continues, with no end in sight.

It is always tempting to ask new questions, which means that scientists are ultimately faced with a huge number of unanswered questions, and with the fact that each answer will probably create more doubts than it will solve. It is like floating in the middle of the Pacific Ocean: we can move a bit towards the edge, but we know that we will never reach it. This mysterious immensity is what makes science so fascinating.

Once we realize that it is impossible to answer all the questions, there are two options: to accept this fact or to attribute the 'answer' to an almighty being - a God. Whichever option we choose does not make any difference to the quality of our research or to our fascination for life's mysteries. As long as we are still looking for the truth, we are on the right track.

Raul Camba

Inorganic Chemistry Laboratory, University of Oxford, South Parks Road, Oxford OX1 3QR, UK

\section{Make space for levity}

Sir - Cosmologists are now getting data at rates greater than those conveniently measured in bits per millennium. Nature and Science have recently presented many interesting articles on the subject. But otherwise well written articles seem to have difficulty describing the effects of a greater than zero cosmological constant. Phrases such as "energy density of empty space", "cosmic repulsion", "large scale repulsive force" 3 , "vacuum energy" ", "mysterious repulsive force" and "cosmic antigravity" are inconsistent with each other, and less than clear.

I would like to propose that the effects of a greater than zero cosmological constant be referred to as 'levity'. In the vernacular, levity is rather the opposite of gravity. It starts with 'l', the Latin equivalent of the
Hellenistic lambda. And, while I make no great claims of being a wordsmith, 'levity' or 'levitational force' seems to read better than any of the alternatives above.

In a field where there are terms such as 'black hole' and 'big bang', and where many researchers report feeling uneasy with a greater than zero cosmological constant, surely a little levity wouldn't hurt.

Dan Nagle

12142 Purple Sage Court, Reston,

Virginia 20194-5621, USA

e-mail:dnagle@erols.com

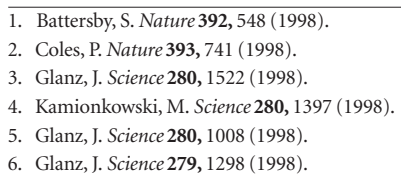

\section{Citation heaven}

Sir - I read the report in Nature with great excitement. At the 1999 Nature Conference on Citation Formats all scientific journals had agreed to use one of three citation formats from 1 January 2000. This was a transition agreement until 1 January 2010 when a single format would be adopted.

Sadly, I awoke from my dream to face another day of formatting my manuscript to the appropriate citation style, and daydreamed of how simple life could be. Brian Dean

Division of Molecular Schizophrenia, Mental Health Research Institute, Parkville, Victoria, Australia 